LAWRENCE LIVERMORE NATIONAL LABORATORY

\title{
Denuded Zones, Diffusional Creep, and Grain Boundary Sliding
}

J. Wadsworth, O.A. Ruano, and O.D. Sherby

\section{August 20, 2001}

2001 Mechanics \& Materials Conference, San Diego, California, June 27-29, 2001 
This document was prepared as an account of work sponsored by an agency of the United States Government. Neither the United States Government nor the University of California nor any of their employees, makes any warranty, express or implied, or assumes any legal liability or responsibility for the accuracy, completeness, or usefulness of any information, apparatus, product, or process disclosed, or represents that its use would not infringe privately owned rights. Reference herein to any specific commercial product, process, or service by trade name, trademark, manufacturer, or otherwise, does not necessarily constitute or imply its endorsement, recommendation, or favoring by the United States Government or the University of California. The views and opinions of authors expressed herein do not necessarily state or reflect those of the United States Government or the University of California, and shall not be used for advertising or product endorsement purposes. 


\title{
Denuded Zones, Diffusional Creep, and Grain Boundary Sliding*
}

\author{
Jeffrey Wadsworth ${ }^{a}$, Oscar A. Ruano ${ }^{b}$ and Oleg D. Sherby ${ }^{\mathrm{c}}$ \\ ${ }^{a}$ Lawrence Livermore National Laboratory, Livermore, CA 94551, USA \\ ${ }^{b}$ CENIM, CSIC, Av. Gregorio del Amo 8, 28040 Madrid, Spain \\ ${ }^{c}$ Department of Materials Science and Engineering, Stanford University, Stanford, CA 94305, \\ USA \\ Prepared to be presented at \\ 2001 Mechanics and Materials Conference \\ (UC San Diego's Center of Excellence for Advanced Materials (CEAM)) \\ June 27-29, 2001 \\ San Diego, California, USA
}

\begin{abstract}
The appearance of denuded zones following low stress creep in particle-containing crystalline materials is both a microstructural prediction and observation often cited as irrefutable evidence for the Nabarro-Herring mechanism of diffusional creep. The denuded zones are predicted to be at grain boundaries that are orthogonal to the direction of the applied stress. Furthermore, their dimensions should account for the accumulated plastic flow.

In the present paper, the evidence for such denuded zones is critically examined. These zones have been observed during creep of magnesium, aluminum, and nickel-base alloys. The investigation casts serious doubts on the apparently compelling evidence for the link between denuded zones and diffusional creep. Specifically, denuded zones are clearly observed under conditions that are explicitly not diffusional creep. Additionally, the denuded zones are often found in directions that are not orthogonal to the applied stress.

Other mechanisms that can account for the observations of denuded zones are discussed. It is proposed that grain boundary sliding accommodated by slip is the rate-controlling process in the stress range where denuded zones have been observed. It is likely that the denuded zones are created by dissolution of precipitates at grain boundaries that are simultaneously sliding and migrating during creep.
\end{abstract}

key words:

\footnotetext{
- This work was also performed under the auspices of the U.S. Department of Energy by the University of California Lawrence Livermore National Laboratory under contract No. W-7405-Eng-48.
} 


\section{INTRODUCTION}

The formation of denuded zones at grain boundaries during creep of particlehardened materials has been observed in several metal-base systems. Examples of denuded zones created during tensile creep of both a magnesium-zirconium hydride alloy and a precipitation strengthened aluminum alloy are shown in Fig. 1[1,2]. The formation of these denuded zones has been cited as unique and compelling microstructural evidence for Nabarro-Herring diffusional $(\mathrm{N}-\mathrm{H})$ creep $[1,3,4]$. This is because, in diffusional creep, atoms flow from grain boundaries that are parallel to the applied tensile stress to those that are perpendicular to it. If an alloy contains a dispersion of an inert second phase, then, following diffusional creep, denuded zones would be expected to form only on grain boundaries that are perpendicular to the applied tensile stress. Additionally, precipitates would be expected to build up on grain boundaries parallel to the applied stress.

Evidence has been presented by the present authors, however, to demonstrate that denuded zones formed during creep, and cited as evidence for $\mathrm{N}-\mathrm{H}$ creep, cannot in fact be attributed to diffusional creep [5-7]. An alternative model for their formation was proposed. The model centers on the dissolution of precipitates at moving grain boundaries that are sliding and migrating during creep. Nabarro [8] refuted this model and stated that the dissolution of precipitates in moving grain boundaries "is not likely to operate" and "cannot account for the observed formation of regions enriched in precipitates, principally on lateral boundaries". It is therefore apparent that the debate on the formation of denuded zones in creep, remains unresolved.

It is the purpose of the present paper to document, assess, and discuss the development of denuded zones during creep of many dissimilar materials. These include reactor-grade magnesium alloys, nickel-base superalloys, and superplastic 7475 aluminum. A major objective is to understand in detail how denuded zones form during creep of these materials.

\section{Denuded zones in magnesium alloys containing dispersoids}

Magnesium-base materials have found applications in nuclear power reactors (9). The design requirements included high resistance to creep at temperatures up to $500^{\circ} \mathrm{C}$, with no more than one-percent deformation in 40,000 hours (4 1/2 years). An extensive creep program was carried out on three reactorgrade magnesium alloys over eleven years in England (1956 to 1967). The 
three alloys were: (1) a $\mathrm{Mg}-\mathrm{Zr}$ alloy containing $\mathrm{ZrH}_{2}$ precipitates (ZA or ZR55), (2) a Mg-1-1.5\%Mn alloy (AM 503), and (3) a Mg-0.8\%Al alloy (Magnox AL80). Denuded zones developed during creep of these materials were first reported in 1963. Squires, et al. (10) described the formation of denuded zones In the ZA alloy. Haddrell (11) noted similar denuded zones in AM 503. Subsequent studies on denuded zones were by Vickers and Greenfield (12), by Pickles (13), by Backofen and his colleagues (14-17), and by McNee (18). With the exception of Vickers and Greenfield, all these investigators on denuded zones, concluded from their studies that diffusional creep was the dominant deformation mechanism. And, specifically, it was concluded by them that the diffusional creep mechanism created the denuded zones.

The present authors (5-7) have pointed out that the presence of denuded zones is a necessary but not sufficient condition for verification of diffusional creep in two-phase materials. The creep behavior must fulfill a number of additional requirements as described by the following equation:

$$
\dot{\varepsilon}=A \cdot\left[\exp -\left(Q_{c} / R T\right] \cdot\left[d^{-p}\right] \cdot[\sigma / E]^{n}\right.
$$

$\dot{\mathcal{E}}$ is the creep rate, $A$ is a constant at a given temperature, $Q_{c}$ is the activation energy for creep, $d$ is the grain size, $p$ is the grain size exponent, $\sigma / E$ is the creep stress divided by the dynamic, unrelaxed elastic modulus, and $n$ is the stress exponent.

As originally described by Nabarro and Herring, in 1948 and 1950 respectively, and based on Eq. (1), there are four requirements for $\mathrm{N}-\mathrm{H}$ creep (19-20). These are: (i) the stress exponent, $n$, must equal one, (ii) the grain size exponent, $p$, must equal -2 , (iii) the activation energy $Q_{c}$ must equal that for lattice self-diffusion, and (iv) the experimentally determined creep rate must equal the theoretically predicted one. (There are also the additional microstructural predictions in systems containing inert particles such as denuded zones on grain boundaries perpendicular to the applied stress, and precipitate buildup on grain boundaries parallel to the applied stress.) It was pointed out by the present authors and their colleagues in the 1990s, that requirements (i) and (iv) were not in fact achieved in any of the magnesiumbase systems $(5,6)$. The stress exponent was found not only to be greater than unity, but typically equal to 4 to 6 . These authors concluded that the experimentally observed high stress exponent of necessity indicated that creep was taking place by a dislocation glide and climb process; therefore, it was not 
possible that diffusional creep could account for the creation of denuded zones, since it was not the operative mechanism based on Eq. (1).

The present authors, however, were unaware at the time of their own publications, that similar objections and conclusions had in fact been published thirty-five years ago. Both Raraty (21) and Vickers and Greenfield (12) had, at that time, also shown that requirements (i) and (iv) were not fulfilled. Their results and conclusions, together with creep data on Magnox AL80 reported by Harris and Jones (22), presented information on the factors influencing creep of the magnesium alloys and will now be reintroduced and considered. As a result of this analysis, a specific model will be presented to explain the origin of denuded zones developed during creep.

The Vickers and Greenfield (12) study in 1967 examined the creep behavior of the hydrided $\mathrm{Mg}-\mathrm{Zr}$ alloy $(\mathrm{ZA})$ at 400 and $450^{\circ} \mathrm{C}$, and showed that denuded zones formed at all stresses. They indicated that the grain size exponent, $p$, was about equal to -2 , the stress exponent, $n$, was about 4 , and the activation energy was about equal to that for lattice self-diffusion of magnesium $\left(D_{L}=10^{-4} \exp [-132 \mathrm{~kJ} / \mathrm{mol} / R T], \mathrm{m}^{2} \mathrm{~s}^{-1}\right)$. The stress exponent in the Vickers and Greenfield study, was about the same as those obtained in other, more recent investigations. It was therefore decided to combine the Vickers and Greenfield data with other published creep data $(9,17,23,24)$, utilizing Eq. (1). The result is shown in Fig. 2 in which the creep rate $\dot{\varepsilon}$, compensated by the grain size, $d$, and the lattice diffusion coefficient of magnesium, $D_{L}$, is plotted as a function of the modulus-compensated stress, $\sigma / E$. Data points representing samples in which denuded zones were observed, are given by filled symbols. The data fall remarkably well on a common straight line with a stress exponent, $n$, equal to 4 . A line is drawn in the figure showing the prediction for diffusional creep.

The data shown in Fig. 2, is convincing proof that denuded zone formation during creep of the hydrided $\mathrm{Mg}-\mathrm{Zr}$ alloy is unrelated to diffusional creep. Vickers and Greenfield (12), in analyzing their own data, arrived at this same conclusion. A similar conclusion was made by Raraty (21) in analyzing creep data for AM 503 (Mg-1.5\%Mn alloy). This magnesium alloy was shown to have formed denuded zones during creep, and their presence was attributed by Haddrell (11) to diffusional creep. Raraty, however, showed that creep data at the same temperature exhibited stress exponents that were on the order of 4 . A high stress exponent $(n=6)$ for AM 503 was also noted by Greenfield and Vickers (25). A stress exponent of $n=4$ or 6 clearly violates the condition for 
diffusional creep that $n=1$. Since the creation of denuded zones in the $Z A$ alloy and in AM 503 cannot be attributed to diffusional creep, it is necessary to search for another mechanism.

Recognizing the need for a different mechanism, Raraty suggested that there is an interchange between manganese atoms in solution and in the $\mathrm{Mg}-\mathrm{Mn}$ precipitate. He stated that "redistribution of the precipitate could occur as a result of stress oriented grain boundary migration during creep". He supported this view by quoting results obtained previously from an electron microprobe analysis of denuded zones by Raraty, Baggott, and E.G. Wilson (26). Raraty concluded that the electron microprobe analysis of "specimens showed a manganese concentration of about $0.8 \mathrm{wt} \%$ in the denuded zone compared with the background value of $1.25 \mathrm{wt} \%$, confirming that the zones were not pure magnesium but contained manganese in solid solution." Vickers and Greenfield suggested a similar mechanism of precipitate redistribution to explain the creation of denuded zones during creep. They concluded that the denuded zones are formed "possibly by re-solution-precipitation processes in volumes which have been swept out by migrating grain boundaries in regions of high vacancy flux (i.e., the zones are caused by creep and do not produce creep strains in themselves)." These postulates are supported by microstructural observations from Herenguel on a $\mathrm{Mg}-\mathrm{ZrH}_{2}$ alloy (27). Figure 3 includes photomicrographs from Herenguel, showing what appears to be the creation of a denuded zone by grain boundary migration. The moving boundary apparently absorbs fine precipitates; then, the precipitates appear to combine to form bigger precipitates. There is an indication of a type of grain boundary dragging process that was proposed by Ashby and Palmer (28). These large precipitates are seen to have a temporary pinning effect on the migrating boundary. The works of Raraty, and of Greenfield and Vickers, were published in 1966 and 1967, respectively. The present authors, with Wolfenstine (5), came to similar conclusions in 1993 (i.e., almost thirty years later).

The mechanisms presented by Raraty, and by Vickers and Greenfield, appear realistic but do not address in detail the creep mechanism that results in the creep behavior shown in Fig. 2. But, creep behavior exhibiting a stress exponent of 4 , with a grain size exponent of $p=-2$, has been observed in other metal-base systems (29-32). Explanations for this type of creep behavior have been proposed based on grain boundary sliding (33-36). The present authors $(35,36)$, for example, have utilized the Ball-Hutchison model of grain boundary sliding (37) to explain a stress dependence of $n=2$. This model is shown in Fig. 4 in which grain boundary sliding is shown to be controlled by dislocation 
generation at regions where blockage for grain boundary sliding occurs. In this model, dislocations glide, pile-up at the opposite side of the grain, and then climb. The pile-up stress leads to a stress exponent of two with $p=-2$. Ruano, Wadsworth, and Sherby (36) extended the model to explain a stress exponent of four observed in a fine-grained stainless steel (38) where $p=-2$. This model utilized an effective diffusion coefficent that incorporated the additive contribution of dislocation pipe diffusion and lattice diffusion to the ratecontrolling climb process. The pipe diffusion coefficient term contains a dislocation density term that increases with increasing stress. The dislocation density was considered as that existing in the vicinity of the grain boundary (i.e., the Gifkins' mantle region (39)). Ruano, et al., assumed that the dislocation density varies with the stress to the two power following the Taylor relation, although phenomenologically, other power relations have been observed by, for example, Mills, Gibeling, and Nix (40). In equation form, creep by grain boundary sliding is described as:

$$
\dot{\varepsilon}=A / d^{2} \cdot\left[D_{L}+50(\sigma / E)^{2} D_{p}\right] \cdot[\sigma / E]^{2}
$$

where $D_{p}$ is the dislocation pipe diffusion coefficient. At low stresses, when the $D_{L}$ term is larger than the $D_{p}$ term, Equation (2) predicts a stress dependence of two. This is the normally observed relation for the majority of fine-grained superplastic materials when creep tested at temperatures above $0.6 T_{m}$ and at low strain rates $(41)$. At high stresses, when the $D_{p}$ term becomes larger than the $D_{L}$ term, Equation (2) predicts a stress exponent of four. This prediction fits in well with the stress exponent observed for the $\mathrm{Mg}-\mathrm{ZrH}_{2}$ material (Fig. 2). The activation energy for creep, however, is closer to that for the lattice diffusion activation energy, $Q_{L}$, than for the expected value for the dislocation-pipediffusion activation energy, $Q_{p}$. Limited studies on diffusion in solids suggest $Q_{p}$ is about $0.65 \mathrm{Q}_{\mathrm{L}}$ but it is conceivable that the ratio is higher for the case of magnesium.

Creep data are available for reactor-grade magnesium materials that exhibit regions of $n=2$ and $n=4$. For example, Fig. 5 shows data for the hydrided $\mathrm{Mg}-\mathrm{Zr}$ alloy (ZA) tested at $400^{\circ} \mathrm{C}$ and for Mg-0.8\%Al (Magnox AL80) tested at $300^{\circ} \mathrm{C}$. These data are compared with an austenitic stainless steel in which the change in stress exponent from 2 to 4 with increase in stress is evident. In the stainless steel study the grain size ranged from 30 to $160 \mu \mathrm{m}$ with $p=-2$ 
observed over both ranges (36). The transition in the stress exponent from $n=2$ to $n=4$, occurs at the same value of the modulus-compensated stress of $\sigma / E=10^{-4}$. The results shown in Figs. 2 and 5 indicate that grain boundary sliding is an important deformation mechanism in creep of the magnesium-base materials. The authors acknowledge that this model revises a previous view in which they proposed that diffusion-controlled dislocation creep was the ratecontrolling-creep process for these materials when $n=4$ to 6 (5).

In the creep analyses made in Figures 2 and 5, the total strain from creep has been used to define the creep rate. It has been proposed by Pickles (13) that the strain associated with denuded zones should be used to calculate the diffusional creep rate; and it is these data that should be compared with the diffusional creep theory. He claimed good agreement. The present authors (12), however, have indicated that Pickles, in discussing his own work, noted that denuded zones were observed in grain boundaries both parallel and normal to the stress axis being somewhat thicker in the latter. The data analyzed by Pickles are shown as square symbols in Figure 5 . His observation refutes a diffusional creep process but is in agreement with the view that grain boundary sliding and grain growth will dissolve the precipitates leading to the formation of denuded zones at all boundaries. Vickers and Greenfield, following the approach of Pickles, also analyzed their data using the thickness of denuded zones as the measure of the creep rate. They found that the strain rate in the denuded zone, was proportional to the fourth power of the stress, just as observed for the total strain rate. This result indicates that the diffusional creep theory is not applicable to interpret the Vickers and Greenfield results.

\section{Proposed Model for Formation of Denuded Zones}

It is our view that the formation of denuded zones during creep is caused by the simultaneous action of grain boundary sliding and grain boundary migration. Grain boundary sliding provides mechanical shearing at the grain boundary to assist the dissolution process. Grain boundary migration introduces a fresh amorphous-like region, possibly quite dissimilar from the original boundary before creep tests, to new areas that assist in the dissolution of precipitates. The dissolved atoms then migrate along the moving grain boundary to redeposit in other regions of the grain boundary where no grain growth occurs. The sequence of events that occur by the proposed model is summarized in Fig. 6 . The grain boundary under a tensile stress is shown shearing and migrating upwardly. The boundary in each sequence is drawn thick to reflect that it is a 
mantle-like region with dislocations located adjacent to the boundary that assist the dissolution and solute migration process. At the beginning of boundary shearing and migration the small zirconium hydride precipitates (shown as small dots) dissolve and migrate along the mantle region. The precipitates that do not dissolve (shown as large dots) are dragged by the migrating boundary. As the boundary moves, more fine precipitates are picked up by the boundary and dissolve. Some of the dissolved solutes will migrate to redeposit onto the dragging precipitates. Other excess solutes will migrate along the concentration gradient toward the non-migrating lateral boundary, or diffuse into the denuded zone region. As a result of the dissolution process, the composition of solute atoms in the denuded zone will be different from the composition in the matrix, and this is invariably observed. Finally, with further boundary migration, the dragged and growing undissolved precipitates will break away from the boundary to become part of the denuded zone.

Experimental evidence of the importance of shearing deformation to the dissolution of so-called insoluble precipitates is provided by the work of Herenguel and Lelong (42) and of Whittenberger (43). Herenguel and Lelong demonstrated that intense shearing during extrusion of an $\mathrm{Al}-1 \% \mathrm{Fe}$ alloy has been shown to dissolve the "insoluble precipitates of $\mathrm{Al}_{3} \mathrm{Fe}$ " and that the dissolved iron reprecipitates as ultrafine particles immediately after extrusion. Similarly, Whittenberger showed that deformation bands created during creep dissolved the gamma prime precipitates in a highly alloyed $\mathrm{Ni}-\mathrm{Cr}$ material.

Our view of denuded zone formation thus leads to the following specific predictions for the formation of denuded zones under conditions that do not require diffusional creep:

- If grain boundary migration occurs in all directions in a given grain, then denuded zones should be observed in longitudinal and transverse boundaries. This prediction is confirmed with the work of Pickles (15) who observed denuded zones in both boundary orientations after creep deformation in tension. Slightly thinner zones were noted on longitudinal boundaries than on transverse boundaries. This indicates that a tensile stress enhances both grain growth and also directional grain growth.

- When grain growth during sliding occurs only in the tensile direction, then denuded zones will be observed only at transverse boundaries. In this case, the grain boundary is located between the denuded zone and the precipitate zone and not in the middle of the denuded zone as required by diffusional 
creep. Microstructural evidence indicates that grain boundaries are in fact rarely observed within the denuded zones created during creep $(10,12,13)$.

- Denuded zones forming under compression creep conditions are expected to form at longitudinal grain boundaries (i.e., those that are parallel to the compression stress). This is because the compression stress on transverse boundaries will inhibit grain growth. In contrast, there is no stress on longitudinal boundaries. Evidence for this prediction is given by Karim, Holt, and Backofen (16).

- There is no reason to expect that grain growth should be identical at opposite sides of a grain boundary. Thus, denuded zones may be expected to form only on one side of the grain. Diffusional creep would, however, predict that both sides of a grain boundary be denuded. Microstructural evidence does not support this prediction for denuded zones apparently formed during diffusional creep (14).

- Denuded zones are often observed to contain coarse precipitates (10). The diffusional creep mechanism demands the absence of precipitates in the denuded zones. The presence of precipitates can be expected, however, if grain boundary migration is the source for formation of denuded zones. Dissolution and recoalescence to form large precipitates at the grain boundary are products of a moving grain boundary, and their breakaway from the moving grain boundary can be expected if the driving force for migration is high. Figure 4 shows a good example of this process.

The creep behavior of several reactor-grade magnesium alloys has been explored in this section. A detailed explanation of the mechanism of forming denuded zones, based on grain boundary sliding and migration, has been proposed. Furthermore, it is postulated that creep deformation, in these alloys, is caused by grain boundary sliding that is rate-controlled by dislocation climb. The same explanation for the creation of denuded zones is proposed, however, for the case where deformation is by a dislocation slip process in which there is no inverse grain size squared relationship. This is because even though dislocation slip dominates deformation, grain boundary sliding and migration processes will still occur, although they will not contribute significantly to the creep strain. An example is shown in Fig. 7, of a multi-step grain boundary sliding and migration process during creep of a coarse-grained pure aluminum material (44). Plastic flow of this material is by diffusion-controlled slip creep; and grain boundary sliding and migration occur as secondary processes. This 
point will become evident in the subsequent discussion on denuded zones in nickel base alloys.

\section{Denuded zones in nickel-base and aluminum-base alloys containing dispersoids}

Denuded zones have been observed in systems other that those observed in magnesium-base alloys. Studies on three nickel-base alloys (45-48) have revealed formation of denuded zones. Among aluminum alloys, it appears that only 7475 aluminum has been reported to show denuded zone formation during creep. The creep characteristics of 7475 aluminum have been evaluated by a number of investigators (2,49-57). It will be shown that under the creep conditions in which the denuded zones formed, these nickel-base and aluminumbase alloys deformed either by grain boundary sliding or by dislocation creep. Grain boundary sliding is proposed as the mechanism when there is a grain size effect where $p=-2$, and the stress exponent is two or greater. Dislocation creep is proposed as the mechanism when there is no grain size effect.

An overview of the creep rate-creep stress relations for the nickel-base and aluminum-base alloys mentioned above is shown in Fig. 8. The graph is plotted as normalized creep rate $\left(\dot{\varepsilon} d^{2} / D_{L}\right)$ as a function of normalized stress $\sigma / E$, and the specific regions where denuded zones were observed are indicated. The Nimonic $80 \mathrm{~A}$ alloy (Ni-20Cr-2.5Ti-1.5Al-0.IC) and the 7475 aluminum alloy (Al-6Zn-2.5Mg-1.4Cu-0.2Cr, $0.06 \mathrm{Fe}-0.05 \mathrm{Si}$ ) exhibit the pattern noted previously with the magnesium-base alloys and the austenitic stainless steel. That is, the stress exponent is two at low stresses and increases to four at high stresses. It is important to note that all these materials were processed by a casting and mechanical working procedure (i.e., they are wrought materials). Denuded zones were noted at several stress levels in these materials. This pattern is similar to that observed by Vickers and Greenfield for the $\mathrm{Mg}-\mathrm{ZrH}_{2}$ material (Fig. 2).

The other two alloys shown in Fig. 8 are nickel-base alloys that were processed by a powder metallurgy route involving mechanical alloying. They are MA 754 (Ni-20 Cr-0.6Al-0.07C-0.6Y ${ }_{2} \mathrm{O}_{3}$ ) and MA 6000E (Ni-15Cr-4.5Al-4W2.5Ti-2Mo-2Ta-1.1 $\mathrm{Y}_{2} \mathrm{O}_{3}-0.15 \mathrm{Zr}-0.05 \mathrm{C}$ ). The compositions of these alloys represent successful metallurgical alloy developments, but are difficult to explain using basic physics principles. The experimental observation is that the creep rate-stress relations do not follow the pattern observed in the wrought 
materials. They show high stress exponents of six and greater. Such creep behavior is attributed to the high level of solute atoms and precipitates introduced by mechanical alloying and severe mechanical working. The MA 754 material was tested in both the longitudinal and transverse direction to the rolled plate direction. The transverse strength is seen to be considerably lower than the longitudinal strength at low stresses, but to be identical in strength at high stress. Denuded zones were observed only at a very low stress, at about the same strain rate for both materials (Fig. 8). Compression creep of MA 6000 alloy revealed denuded zones at low stress. The creep behavior of each alloy is covered in detail in the following sections.

\section{Denuded zones in nickel-base alloys}

The MA 754 material is a severely worked powder metallurgy product. The result is an elongated grain structure. The grain lengths are $530 \mu \mathrm{m}$ in the longitudinal direction, $180 \mu \mathrm{m}$ in the long transverse direction, and $115 \mu \mathrm{m}$ in the short transverse direction (47). It will be shown that the influence of grain boundary sliding and dislocation creep can explain the results obtained in MA 754 documented in Fig. 8 . It is generally accepted that grain boundary sliding contributions to creep diminish with increase in stress (i.e., in strain rate). Thus, the same strength is achieved at high strain rates in MA 754, independent of direction of testing, because grain boundary sliding is not contributing to the deformation process. Crystallographic texture would not be an important factor because of the many slip systems available in face-centered-cubic materials (58). Thus, the strength anisotropy at low stresses must arise from the significance of grain boundary sliding. A schematic illustration is shown in Fig. 9, of the type of elongated structure expected in a heavily extruded powder metallurgy product. This structure depicts how grain boundary sliding can readily occur when tested in a transverse direction, but cannot occur when tested in the longitudinal direction. Creep tests in the transverse direction in compression are predicted to show the sample deforming only in one direction much like logs rolling over each other. This anisotropy in plastic flow, with accompanying anisotropy in strength, has been shown for extruded sintered aluminum powder (SAP) (59). The model shown in Fig. 9 would indicate that the appropriate dimension to be used for grain size in equations for grain boundary sliding (or diffusional creep) should be the transverse grain size. For the case of a sheet or plate material, it should be the average of the transverse grain size in the long and short directions. 
The proposed model for the creep of transverse-tested MA 754 alloy indicates that a grain size effect should be expected for different grain sizes in dispersion-strengthened $\mathrm{Ni}-\mathrm{Cr}$ alloys processed by powder metallurgy methods. An analysis of creep data for T-D Nichrome $(60,61)$ revealed that the creep rate could be described using a grain size dependence of $p$ equal to about -2 , with a value of the activation energy for creep equal to that for lattice diffusion of nickel in Nichrome. These data are plotted as $\dot{\varepsilon} \mathrm{d}^{2} / \mathrm{D}_{\mathrm{L}}$ as a function of $\sigma / E$ in Fig. 10. The data for MA 754 are emphasized by a thick line and thinner lines connect other individual grain size studies. Considering the wide range of grain sizes studied (6.6 to $337 \mu \mathrm{m}$ ), the correlation can be considered to be quite good. The stress exponent appears to increase with increasing stress. It is slightly above four for the finest grain size material at low stresses, and then increases to about six up to $\sigma / E=10^{-3}$. At creep rates above this value of $\sigma / E$ it is proposed that the contribution of grain boundary sliding is negligible and creep is controlled solely by dislocation processes. The slope is eight and is related to constant structure dislocation creep (60). Based on all correlations considered in this paper, where $p=-2$, a grain boundary sliding mechanism for creep, accommodated by slip, is evident. It is concluded that the denuded zones noted by Whittenberger in MA754, tested in the transverse direction, are created by a grain boundary sliding process accommodated by slip.

The creep relation for grain boundary sliding is proposed to be described as:

$$
\dot{\varepsilon}=\left[A / d^{2}\right] \cdot\left[D_{L}\right] \cdot[\sigma / E]^{n}
$$

where $n$ increases with increase in stress following the pattern of two at low stresses, then increasing to four, and finally to six. If the model of Ruano, et al., is essentially correct, it requires modifying the dislocation density at grain boundaries to vary with higher powers of the stress than that appearing in the Taylor relation. Additionally, the higher values of activation energy for creep, $Q_{c}$, than those associated with dislocation pipe diffusion need to be resolved. All the alloys investigated had a high concentration of solute atoms, and their presence may contribute to altering the activation energy for dislocation pipe diffusion in such a way that a value about equal to lattice diffusion becomes rate-controlling. 
The proposed model for creep of the longitudinal-tested MA 754 alloy (Fig. 9) predicts that there should be no grain size effect, inasmuch as grain boundary sliding cannot occur. This is confirmed by the creep data shown in Fig. 11. The creep data for the longitudinal-tested MA 754 alloy is shown to superimpose with the data for single crystalline T-D Nichrome shown in the same figure $(61,62)$. In addition, the creep data for the coarse-grained T-D Nichrome material that did not show creep strength anisotropy is included in the figure. The transverse and longitudinal data of this coarse-grained material is also found to superimpose on the other data. These superpositions are proof that the longitudinal-tested MA 754 is deforming by a dislocation creep process and the formation of denuded zones in this sample is caused by grain boundary migration. Denuded zones were not observed in creep of longitudinal samples of MA754 by Stephens and Nix (63). The downward curvature noted in the central portion of the creep rate-stress data (Fig. 11) arises from a threshold stress as a result of solute drag of dislocations $(60,62,64)$.

The creep properties of MA 6000 evaluated by Timmins and Arzt, at $1323 \mathrm{~K}$, are plotted in Fig. 12. The grain size was about $300 \mu \mathrm{m}$ in the longitudinal direction and $100 \mu \mathrm{m}$ in the long transverse direction. The material was tested in compression in the long transverse direction. Denuded zones were observed only at the lowest stress used by the authors (120 MPa). The creep behavior of MA 6000 was also studied by Whittenberger (43). This material had a grain size of several centimeters (i.e., greater than $10,000 \mu \mathrm{m}$ ) in the longitudinal direction and several millimeters (greater than $1000 \mu \mathrm{m}$ ) in the long transverse direction. This huge grain size was achieved by zone annealing the mechanical-processed-PM material at $1533 \mathrm{~K}$ in a furnace traveling at $6 \mathrm{~cm}$ per hour. The creep data documented by Whittenberger at 1255 and $1365 \mathrm{~K}$, was interpolated to $1323 \mathrm{~K}$ to compare with the Timmins and Arzt study. The two sets of data are compared in Fig. 12, and the superposition of data would indicate that there is no grain size effect. SEM photographs by Whittenberger indicate zones that suggest slip bands and grain boundary sliding "had dissolved and redistributed the gamma prime precipitates." These zones were observed at $305 \mathrm{MPa}$ (Fig. 12). It is concluded that the denuded zones observed by Timmins and Artz are a result of dislocation creep involving grain boundary migration at boundaries that are parallel to the compression stress. The zones cannot be attributed to diffusional creep.

The remaining nickel-base alloy shown in Fig. 8 is the Nimonic $80 \mathrm{~A}$ studied by Gibbons (45). Gibbons concluded "that a diffusional creep mechanism may explain the formation of the precipitate free zones". Nimonic 
$80 \mathrm{~A}$ is a wrought nickel-chromium base alloy containing gamma-prime precipitates. Its creep behavior is similar to those other wrought materials in which denuded zones were observed. A stress exponent of about two at low stresses increasing to about four with an increase in stress is observed, and the compensated creep rates are faster than those predicted by the diffusional creep relationship. It is therefore concluded, as with the other studies, that the denuded zones formed during creep arise from a grain boundary sliding and migration process. Support for this deformation process is provided from Gibbons' own work by electron transmission-microscopy observations. Gammaprime precipitates are observed in the denuded zones and they are larger than those in the grain interior. Polygonization is seen in the denuded zones but not elsewhere in the two-phase region. The presence of dislocations adjoining the grain boundary is a necessary feature of explaining the stress exponent of four and above, in the grain-boundary sliding model developed by the authors.

\section{Denuded zones in aluminum-base alloys}

The creep behavior of 7475 aluminum has been extensively studied by a number of investigators $(2,49-57)$. This fine-grained material (10 to 25 microns) has been shown to be superplastic by all investigators, and denuded zones were noted in most of the studies.

The creep data from all investigators is given in Fig. 13. The data fit the proposed model remarkably well and show the trend expected by the grainboundary sliding model. That is, the stress exponent was two at low stresses and increased to four at high stresses. Exceptions to the trend are values of $n$ about equal to one observed at low stresses and at the highest temperature of testing (52). Addabo, et al. (55), however, showed that this low value of $n$ was obtained because the change in structure with straining was not taken into account. The value of $n$ was shown to be equal to two when tests were performed under constant structure conditions.

Denuded zones observed in 7475 aluminum cannot be a result of diffusional creep. The principal reasons for this conclusion are that the stress exponents for creep are not unity and the creep rates are considerably higher than those predicted by the diffusional creep theory. In addition, the microstructural evidence obtained on denuded zones in 7475 is not consistent with predictions from diffusional creep. For example, Wert and Varloteaux (49), Cao, et al. (2), and Bang, et al. (57) show that denuded zones form at both transverse and longitudinal boundaries under uniaxial stress. Koch (50) has 
shown that the type of stress has an influence on the formation of denuded zones. Under a uniaxial tensile stress, for example, the denuded zones were concentrated mainly on grain boundaries normal to the stress, whereas, under biaxial stress the zones were found on the entire circumference. In microprobe analyses of the composition of the denuded zone, Koch deduced that the increased concentration of magnesium, zinc, and copper in the denuded zones was the result of dissolution of the particles at the moving grain boundary. Zelin (56) examined the microstructure of superplastically-stretched cylindrical cups and concluded that the denuded zones were created by grain boundary shearing and migration controlled by shearing stresses and not by tensile stresses. A diffusional creep process cannot explain any of these results. On the other hand, the denuded zone formation in 7475 aluminum is compatible with a grain boundary sliding and migration process.

\section{Marker movement on surfaces in relation to grain boundaries}

It has been proposed by Langdon (65), by Greenwood (66), and by McNee et al. (67) that the movement of surface markers after creep can be used to identify the action of diffusional creep. Specifically, the inward movement of two adjacent markers on one side of a grain boundary with respect to the same two markers on the other side of a grain boundary was considered to be proof of a diffusional creep process. This is because diffusional creep can remove material from one side of the grain boundary in relation to the other side. This type of marker displacement is shown in Fig. 14A after creep of coarse-grained pure aluminum $(2500 \mu \mathrm{m})$ at $700 \mathrm{~K}(44)$. The observed displacement cannot be a result of diffusional creep. This is because the contribution of diffusional creep during deformation of the coarse-grained material is negligible (the predicted creep rate is a million times slower than the actual creep rate). A more likely explanation is the process of grain boundary sliding and migration. This is shown by the expanded photomicrograph of Fig. 14A given in Fig. 14B. It is concluded that the scribe-marker-displacement model proposed by Langdon and by Greenwood is not, in fact, a unique microstructural method with which to identify diffusional creep.

\section{CONCLUSIONS}

It is concluded that denuded zones cannot be the result of diffusional creep. The present paper provides evidence that denuded zones created during creep arise from the dissolution of precipitates at grain boundaries at sites where 
grain boundary shearing and/or migration take place. When the creep rate dependence on grain size varies with the reciprocal of the grain size squared, the deformation process is that of grain boundary sliding accommodated by slip. It cannot be that of diffusional creep because the experimental creep rate does not agree quantitatively with the predicted creep rate and the experimentally measured stress exponent is not unity.

The Nabarro-Herring diffusional creep theory is the most elegant of all creep theories. The model is rigorous and contains no adjustable parameters. Grain boundaries are considered as the sources and sink of vacancies. The concept of vacancy creation at grain boundaries and the motion of vacancies under a concentration gradient is fundamentally sound. This brilliant idea has been the basis of other creep theories involving dislocation motion and/or climb. In these cases, the sources and sinks of vacancies are at moving dislocation sites and not at grain boundaries. It is the present authors' view that grain boundaries in materials are not good sources and sinks of stress-created vacancies. This is because impurities segregate at grain boundaries and their presence does not allow the formation of stress-created vacancies as envisioned in the Nabarro and Herring models. Perhaps creep studies on extremely high-purity polycrystalline materials can lead to results in agreement with the Nabarro-Herring diffusional creep relation at exceptionally low stresses.

The present paper provides evidence that denuded zones created during creep arise from the dissolution of precipitates at grain boundaries at sites where grain boundary shearing and migration take place.

\section{REFERENCES}

(1) O.D. Sherby, and P.M. Burke, Progr. Mater. Sci. 13, 325 (1967).

(1) Wei-di Cao, Xiao-Ping Lu, A.F. Sprecher and Hans Conrad, in Superplasticity in Aerospace $U$, Terry R. McNelley and $H$. Charles Heikennen (eds), The Minerals, Metals and Materials Society, Warrendale, PA, 269-283 (1990).

(3) B. Burton, in Diffusional Creep of Polycrystalline Materials, Trans. Tech. Pub., Switzerland (1977).

(4) J.P. Poirer, in Creep of Crystals, Cambridge University Press, Cambridge, England (1985). 
(5) J. Wolfenstine, O.A. Ruano, J. Wadsworth and O.D. Sherby, Scr. Metall. Mater. 29, 515 (1993).

(6) O.A. Ruano, O.D. Sherby, J. Wadsworth and J. Wolfenstine, Scr. Mater. 38, 1307 (1998).

(7) Jeffrey Wadsworth, Oscar A. Ruano and Oleg D. Sherby, in Creep Behavior of Advanced Materials for the 21 $21^{\text {st }}$ Century, Rajiv S. Mishra, Amija K. Mukherjee, and K. Linga Murty (eds), TMS, Warrendale, Ohio, 1999, 425439.

(8) F.R.N. Nabarro, in Creep Behavior of Advanced Materials for the $21^{\text {st }}$ Century, Rajiv S. Mishra, Amija K. Mukherjee, and K. Linga Murty (eds), TMS, Warrendale, Ohio, 1999, 391-395.

(9) P. Greenfield, C.C. Smith, and A.M. Taylor, Trans. AlME_221, 1065 (1961).

(10) R.L. Squires, R.T. Weiner, AND M. Philips, J. Nucl. Mater__8, 77 (1963).

(11) V.J. Haddrell, J. Nucl. Mater. 18, 231 (1966).

(12) W. Vickers and P. Greenfield, J. Nucl. Mater. 24, 249 (1967).

(13) B.W. Pickles, J. Inst. Met. 95333 (1967).

(14) Walter A. Backofen, Francis J. Azzarto, G.S. Murty, and Stanley W. Zehr, in Ductility, ASM Seminar, October 14 to 15, 1967, American Society for Metals, Metals Park, OH, pp 279-310.

(15) A. Karim, D.L. Holt, and W.A. Backofen, Trans. AIME 245, 2421 (1969).

(16) A. Karim, D.L. Holt, and W.A. Backofen, Trans. AIME 245, 1131 (1969).

(17) A. Karim, in Ultrafine-Grain Metals, J.J. Burke and V., Weiss (eds), Syracuse University Press, 1970, p. 295.

(18) K. R. McNee, Microstructural Features of Low Stress Creep in Pure Metals and Precipitation Hardened Alloys, Ph.D. Dissertation, May 2000, Department of Engineering Materials, Sheffield University, Sheffield, Great Britain.

(19) F.R.N. Nabarro, Report of a Conference on the Strength of Solids (Bristol), The Physical Society, London, 75-90 (1948).

(20) C. Herring, J. Appl. Phys. 21, 437 (1950).

(21) L.E. Raraty, J. Nucl. Mater. 20, 344 (1966). 
(22) J.E. Harris and R.B. Jones, An Analysis of Magnox AL80 Secondary Creep Rate, Berkeley Nuclear Laboratories (CEGB Report RD/B/R.144) July 1963.

(23) J.E. Harris and R.B. Jones, J. Nucl. Mater. 10, 360 (1963).

(24) J.E. Harris, Met. Sci. J. Z, 1 (1973).

(25) P. Greenfield and W. Vickers, J. Nucl. Mater. 22, 77 (1967).

(26) L.E. Raraty, R. Baggott and E.G. Wilson, J. Inst. Met. 93, 134 (1964).

(27) J. Herenguel, Mater. Res. 1, 65 (1962).

(28) M.F, Ashby and I.G. Palmer, Acta Metall. 15, 420 (1967).

(29) F. Garofalo, W.F. Domis and F. von Gemmingen, Trans. AIME 230, 1460 (1964).

(30) T.H. Alden, Trans. Am. Soc. Met. 61, 559 (1968).

(31) S.A. Shei and T.G. Langdon, Acta Metall. 26, 639 (1978).

(32) T. Yamane, N. Genma and Y. Takahashi, J. Mater. Sci. 19, 263 (1984).

(33) B. Burton, Scr. Metall._3, 247 (1969).

(34) D.K. Matlock and W.D. Nix, Metall. Trans. 5.961 (1974).

(35) O.A. Ruano, A.K. Miller and O.D. Sherby, Mater. Sci. Eng. 51,9 (1981).

(36) O.A. Ruano, J. Wadsworth and O.D. Sherby, Mater. Sci. 20, 3735 (1985).

(37) A. Ball and M.M. Hutchison, Met. Sci. J. 3, 1 (1969).

(38) T. Yamane, N. Genma and Y. Takahashi, Mater. Sci. 19, 3171 (1984).

(39) R.C. Gifkins, Mater. Charact. 32, 59 (1994).

(40) M.J. Mills, J.C. Gibeling, and W.D. Nix, Acta Metall. 33, 1503 (1985)

(41) Oleg D. Sherby and Jeffrey Wadsworth, Prog. Mater. Sci. 33, 169 (1989).

(42) J. Herenguel and P. Lelong, Revue de Metallurgie 55, 1057 (1958).

(43) J. D. Whittenberger, Metall. Trans. 15A 1753 (1984).

(44) B. Fazan, O.D. Sherby and J.E. Dorn, Trans. AIME 200, 919 (1954).

(45) T.B. Gibbons, Mater. Sci_6. 13 (1972). 
(46) J. Daniel Whittenberger, Metall. Trans. A, 8A, 1155 (1977).

(47) J. Daniel Whittenberger, Metall. Trans. A, 8A, 1863 (1977).

(48) R. Timmins and E. Artz, Scr. Metall. 22, 1353 (1988).

(49) J.A. Wert and A. Varloteaux, in Aluminum Alloys: Their Physical and Mechanical Properties, E.A. Starke and T.H. Sanders (eds), EMAS, Warley, U.K., Vol II, 1255-1267 (1986).

(50) Ursula Koch, in Superplasticity in Aerospace H.C. Heikkenen and T.R. McNelley (eds), TMS, Warrendale, PA, 115-132 (1988).

(51) Dong H. Shin, Ki S. Kim, Dong W. Kum, and Soo W. Nam, Metall. Trans. A 21A 2729 (1990).

(52) C.H. Hamilton, C.C. Bampton and N.E.Paton, in Superplastic Forming of Structural Alloys, N.E, Paton and C.H. Hamilton (eds), TMS-AIME, Warrendale, PA. 173-189 (1982).

(53) J.M. Belzunce, Engineer's Dissertation, Stanford University (1983).

(54) M.K. Rao and A.K. Mukherjee, Mater. Sci. Eng. 80, 181 (1986).

(55) H.E. Addabo, G. Gonzales-Doncel, O.A. Ruano, J.M. Belzunce and O.D. Sherby, J. Mater. Res ¿4, 587 (1989).

(56) M.G. Zelin, J. Mater. Sci. 32, 1075 (1997).

(57) W. Bang, T.K. Ha and Y.W. Chang, in Superplasticity in Advanced Materials, Namas Chandra, Ed. Materials Science Forum, 357-359, 171176 (2001).

(58) C.R. Barrett, J..L. Lytton, and O.D.Sherby, Trans. AIME 239,170 (1967).

(59) Charles L. Meyers Jr., John C. Shyne and Oleg D. Sherby, J. Australian Institute of Metals 8, 171 (1963).

(60) Jerhong Lin and Oleg D. Sherby, Res. Mechanica 2, 251 (1981).

(61) R.D. Kane and L.J. Ebert, Metall. Trans. ZA, 133 (1976).

(62) R.W. Lund and W.D. Nix, Acta Met. 24, 469 (1976).

(63) J.J. Stephens and W.D. Nix, Metall. Trans, 16A, 1307 (1985).

(64) O.D. Sherby and E.M. Taleff, Mater. Sci. and Eng. A, in press, 2001. 
(65) T.G. Langdon, Scr. Mater. 35, 733 (1996).

(66) G.W. Greenwood, in Creep Behavior of Advanced Materials for the 21st Century, Rajiv S. Mishra, Amija K. Mukherjee, and K. Linga Murty (eds), TMS, Warrendale, Ohio, 1999, 413-424.

(67) K.R. McNee, G.W. Greenwood, and H. Jones, Scripta Mater. 44, 351 (2001). 


\section{Figure Captions}

Figure 1. Denuded zones created during creep in tension. a) Magnesiumzirconium hydride polycrystal showing denuded zones principally at grain boundaries experiencing a tensile state. b) 7475 aluminum showing denuded zones at grain boundary experiencing tensile and shear stresses.

Figure 2. Creep of magnesium-zirconium hydridè materials normalized by grain size and temperature as a function of modulus-compensated stress. The filled symbols indicate samples where denuded zones were observed.

Figure 3. Examples of a magnesium-zirconium hydride sample heated to 550$575^{\circ} \mathrm{C}$ showing coarsening and unpinning of particles at the grain boundary.

Figure 4. Model illustrating grain boundary sliding accommodated by dislocation motion involving the sequential steps of glide and climb (after Ball and Hutchison).

Figure 5. Grain size compensated creep rate as a function of moduluscompensated stress for two magnesium alloys and for an austenitic stainless steel illustrating transition in stress exponent from 2 to 4 with increase in stress.

Figure 6. Schematic illustration of the proposed formation of denuded zones according to the following: (1) small zirconium hydride particles dissolve at the shearing-and-migrating grain boundary; (2) undissolved particles are dragged by the grain boundary; (3) the dragged particles grow bigger as small particles dissolve; (4) some big particles will break away from the migrating grain boundary and (5) solute atoms diffuse along concentration gradient to lateral boundaries and deposit on existing particles of $\mathrm{ZrH}_{2}$.

Figure 7. Multiple boundary shearing and migration in high purity aluminum during creep at $1.7 \mathrm{MPa}$ at $474^{\circ} \mathrm{C}$.

Figure 8. Alloy systems where denuded zones have been observed are indicated by the symbol D.Z. For the aluminum and nickel alloys depicted the creep mechanism is either that of grain boundary sliding accommodated by slip or that of diffusion-controlled dislocation creep. 
Figure 9. Schematic illustration of the grain boundary structure in heavilyextruded powder-metallurgy nickel-based alloys.

Figure 10. The grain-size and temperature-compensated strain rate is shown plotted as a function of modulus-compensated stress for a number of nickelbase powder-metallurgy alloys where the stress exponent ranges from 4 to 8 . Grain-boundary sliding accommodated by slip is the dominant deformation mechanism. The single test where denuded zones were observed is indicated.

Figure 11. The lattice-diffusion-compensated strain rate is plotted as a function of stress for a number of nickel-base alloys where the grain boundary is not contributing to the creep process. Diffusion-controlled dislocation creep is the dominant deformation mechanism. The single test where denuded zones were observed is indicated.

Figure 12. The creep rate of a nickel-base MA6000 alloy is plotted as a function of modulus-compensated stress illustrating denuded zone formation at high and at low strain rate. Diffusion-controlled dislocation-creep is the dominant deformation mechanism.

Figure 13. The grain-size and temperature-compensated strain rate is plotted as a function of modulus-compensated stress for 7475 aluminum from several investigators.

Figure 14. Grid-line observation after creep $(\varepsilon=0.11)$ of coarse-grained pure aluminum at $1.7 \mathrm{MPa}$ and $427^{\circ} \mathrm{C}$. a) The two outer vertical grid lines at the bottom of the figure are seen to move inward in contrast to the two vertical grid lines at the top of the figure. b) The region surrounding a) is shown in b) indicating the complex deformation of the grid lines near a grain boundary region as a result of grain boundary shearing and migration processes. 

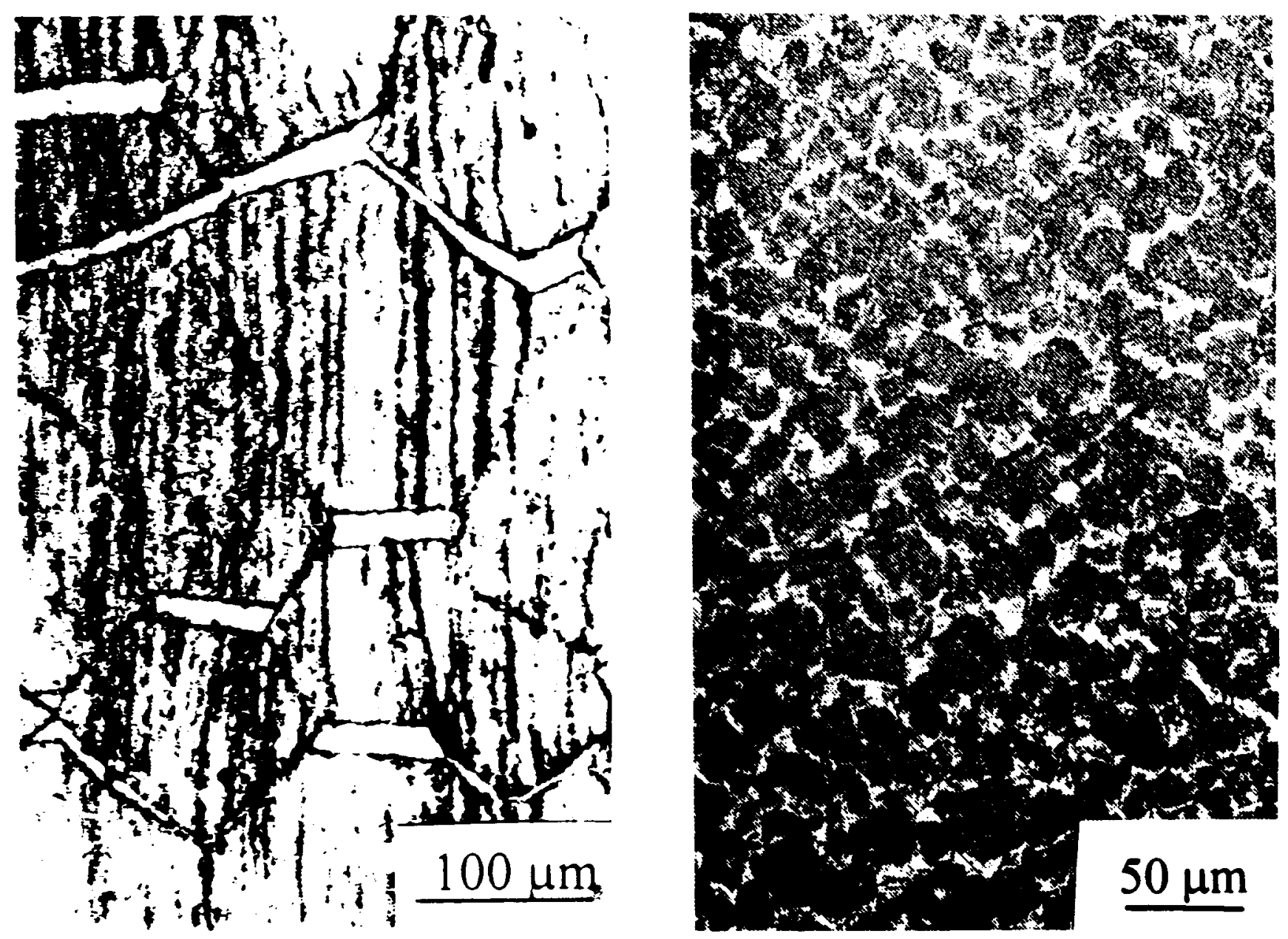

Fig. I

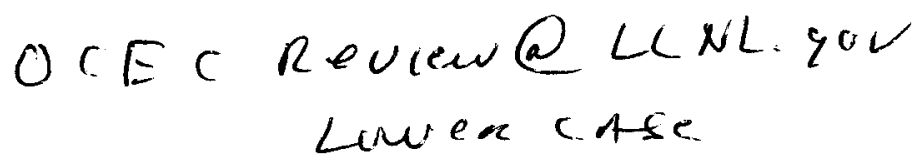




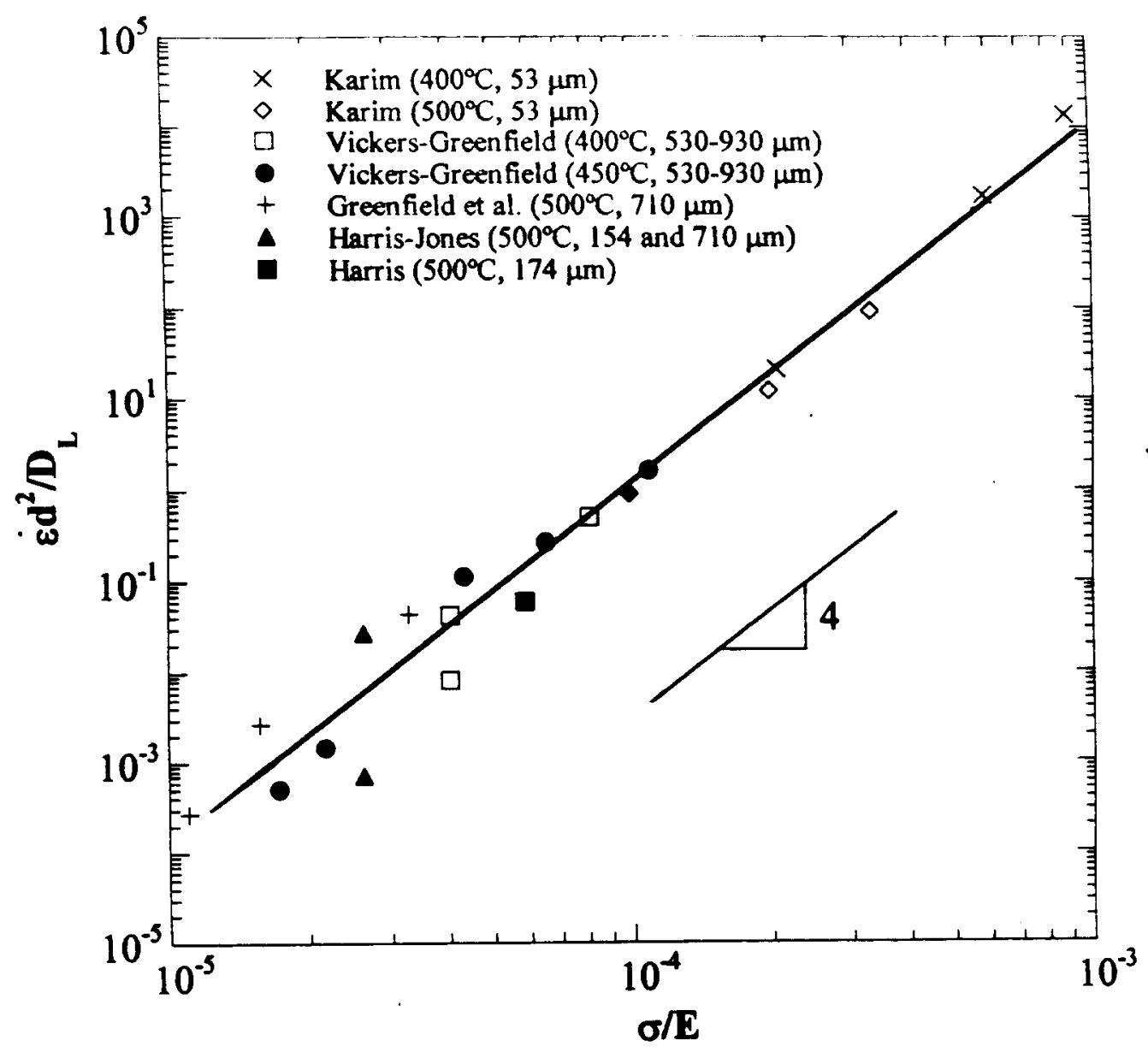

$=$

Fig. 2 

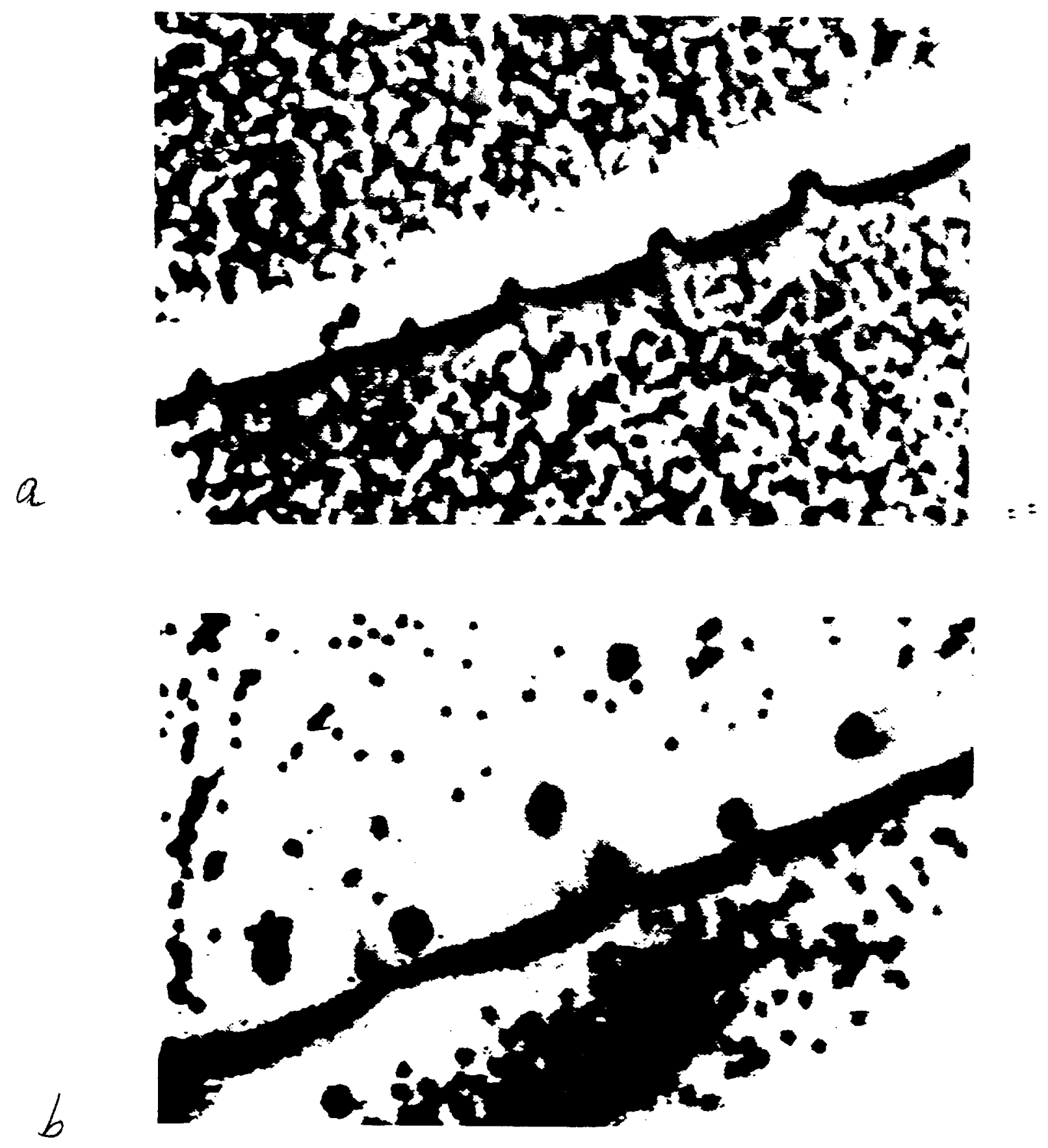

Fig. 3 


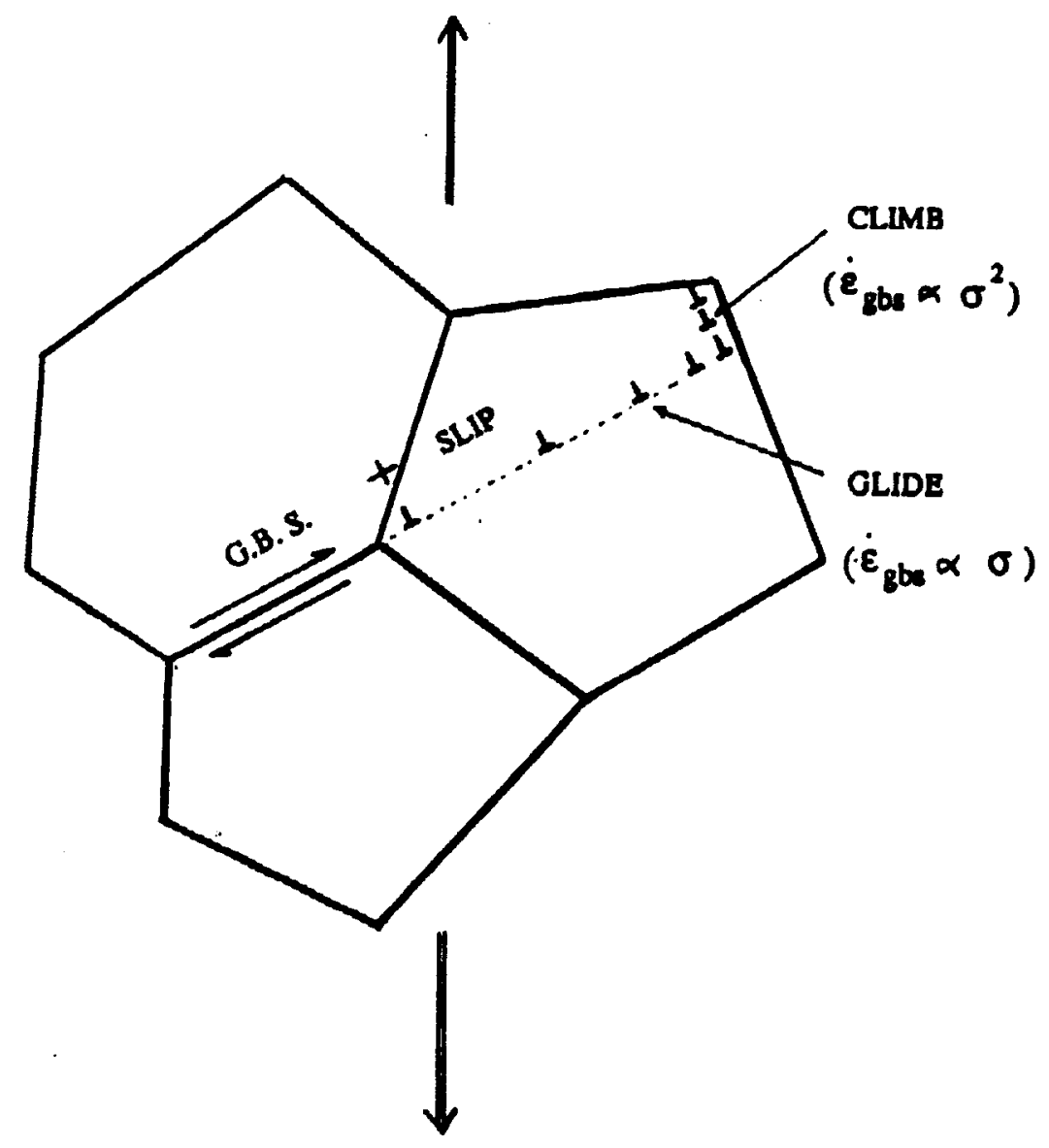

Fig. 4 


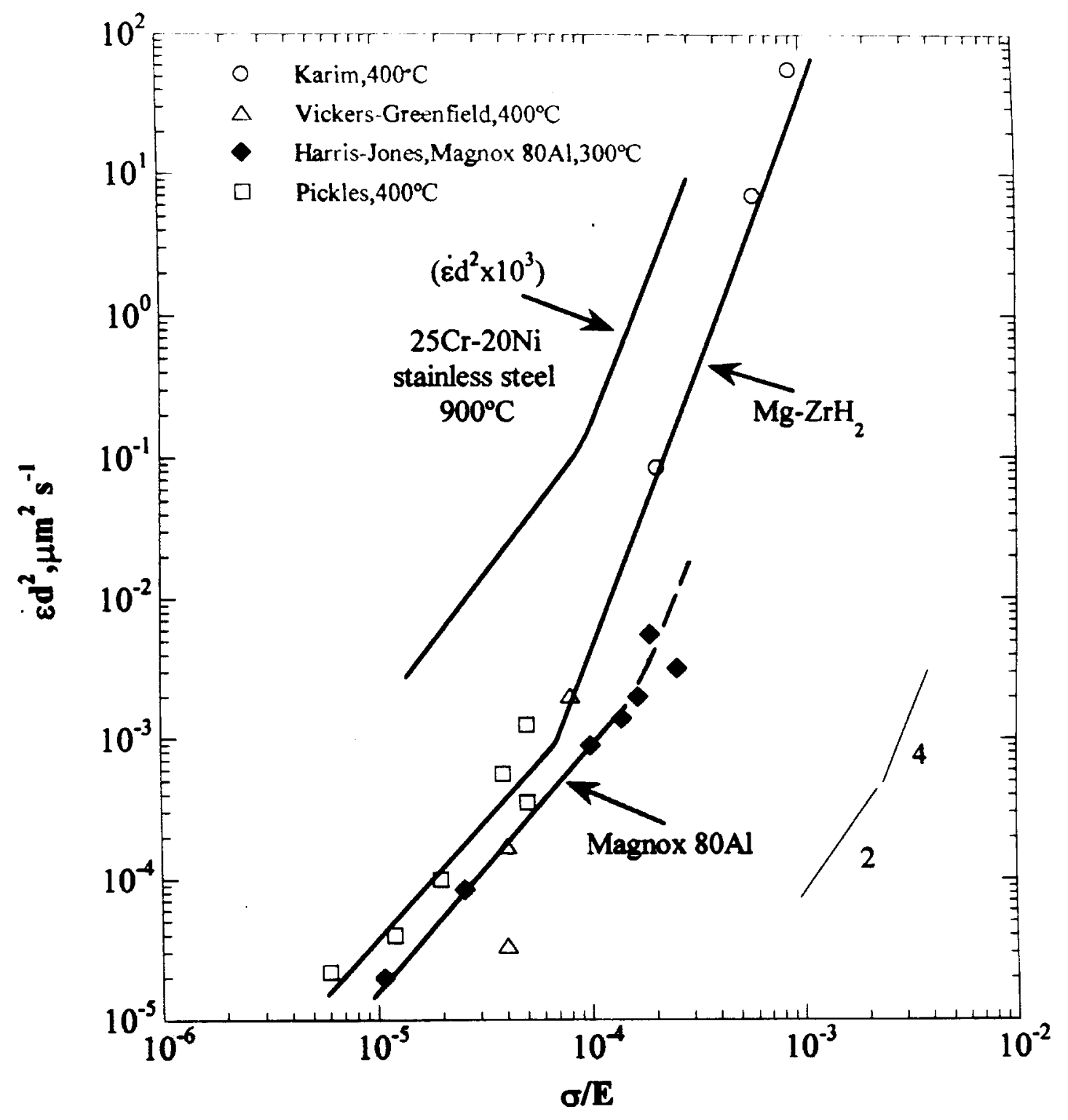

Fig. 5 


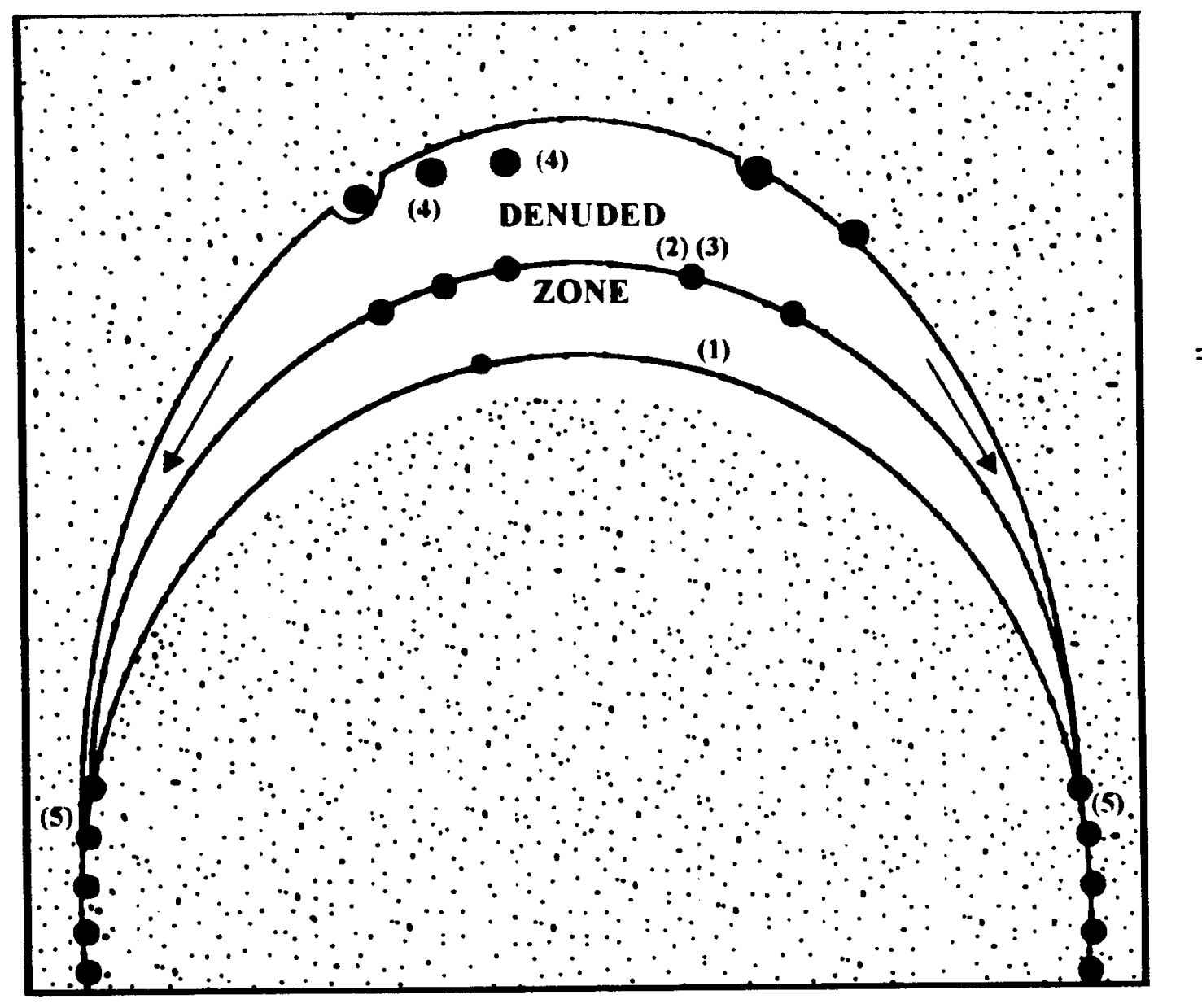

Fig. 6 


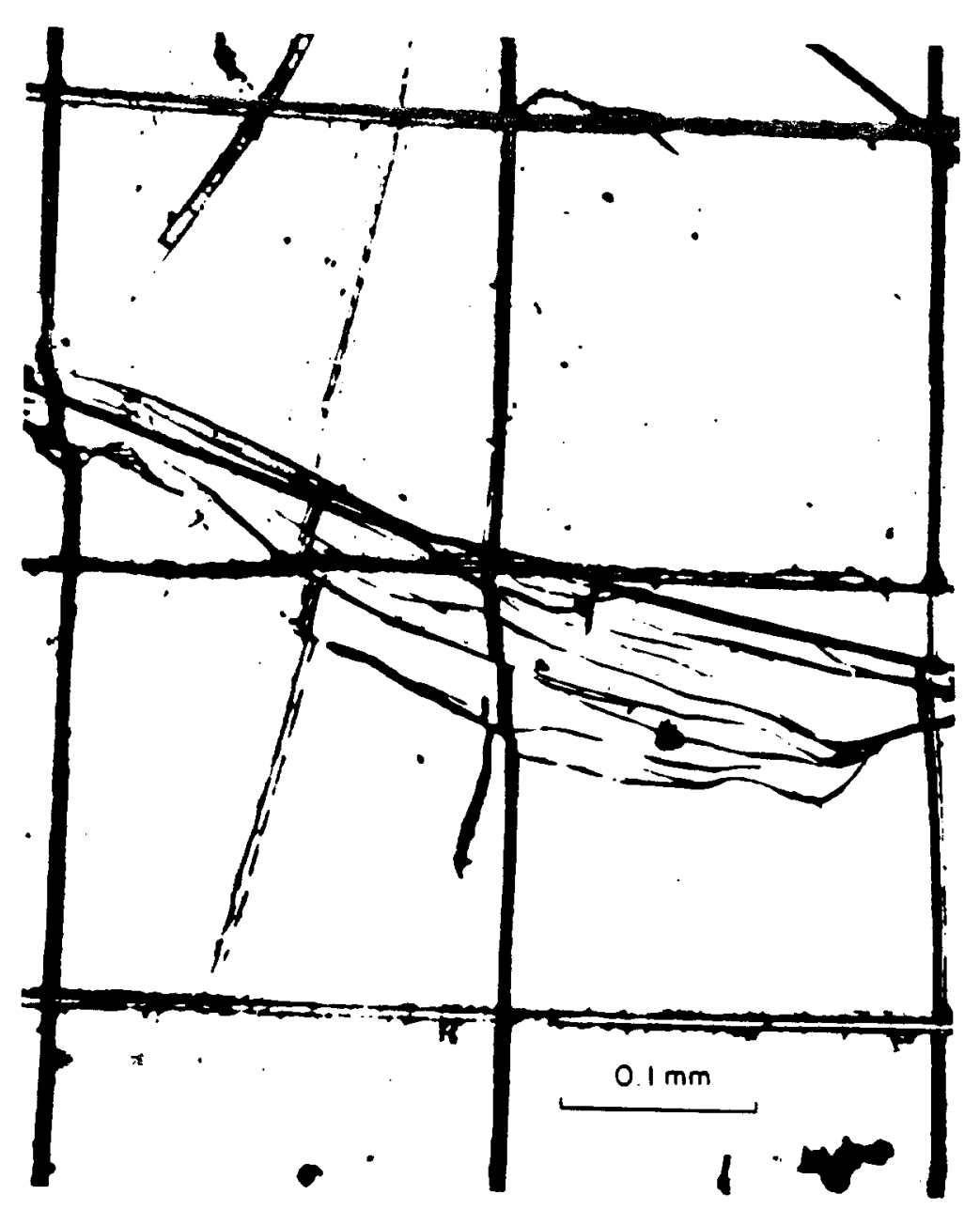

Fig. 7 


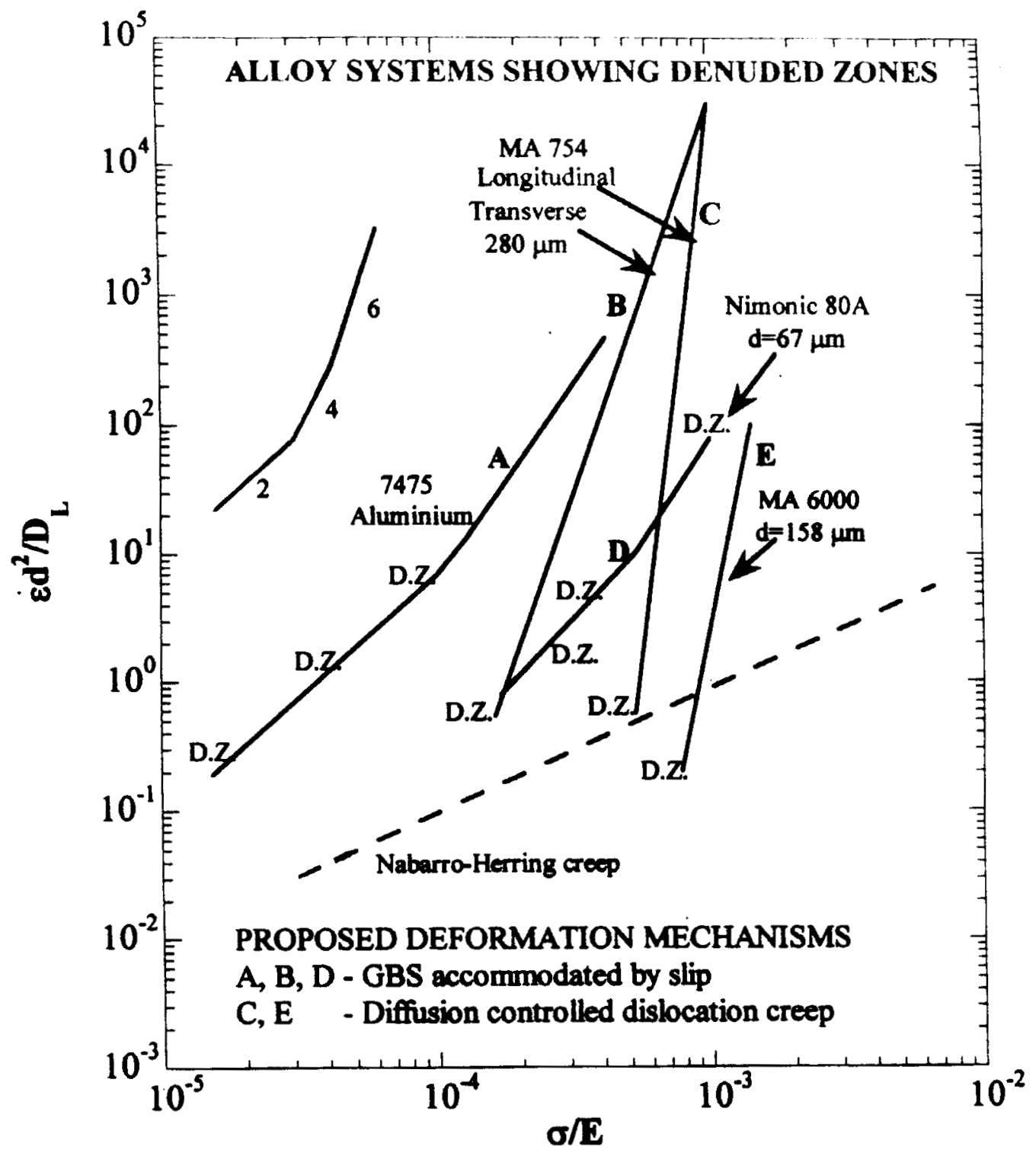

$=$

Fig. 8 


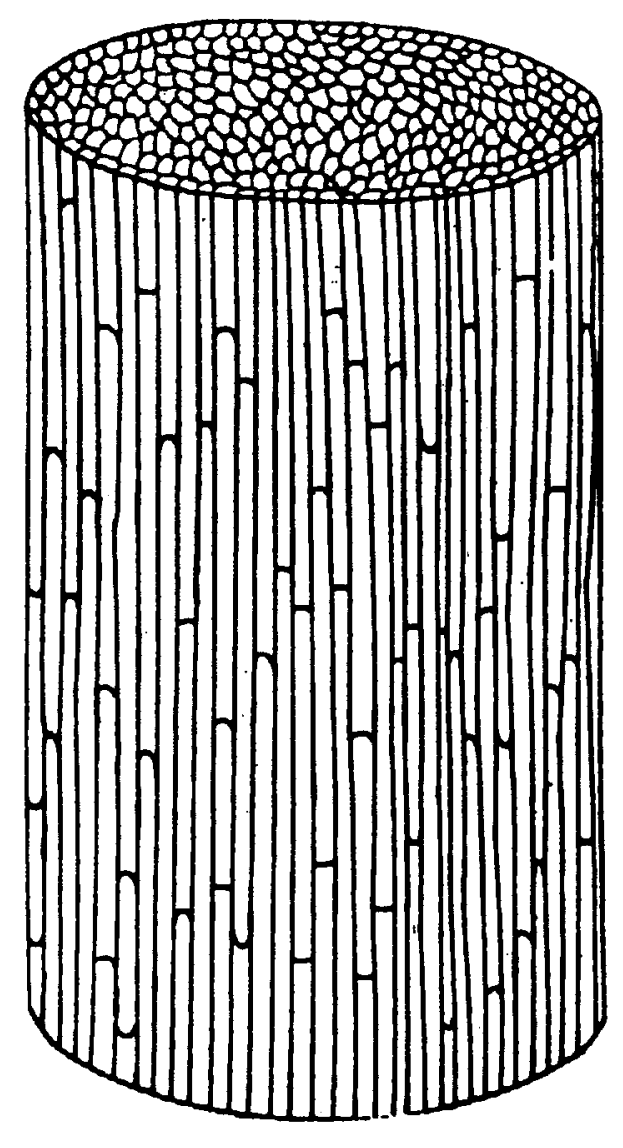

Fig-9 


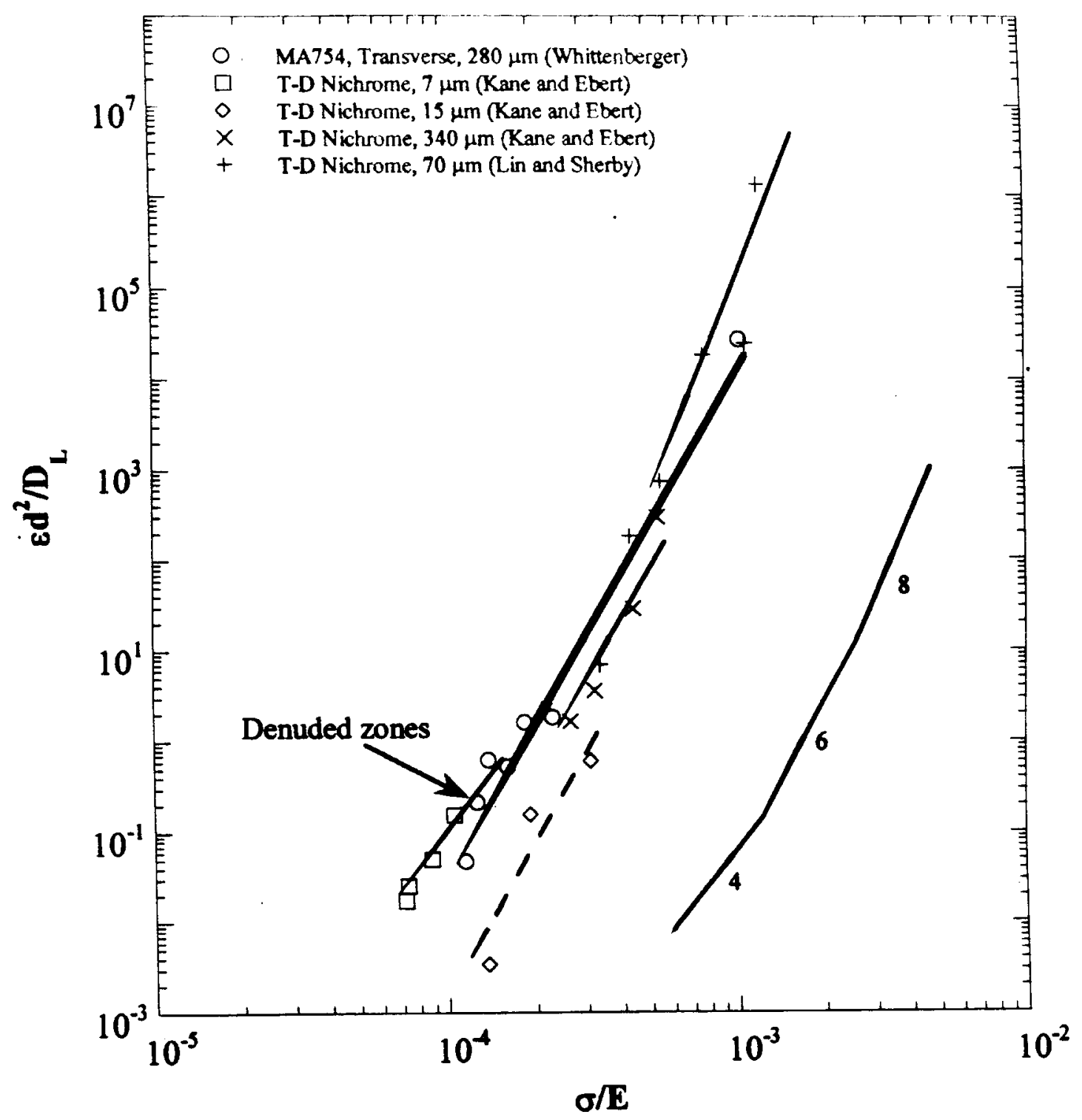

Fig D 


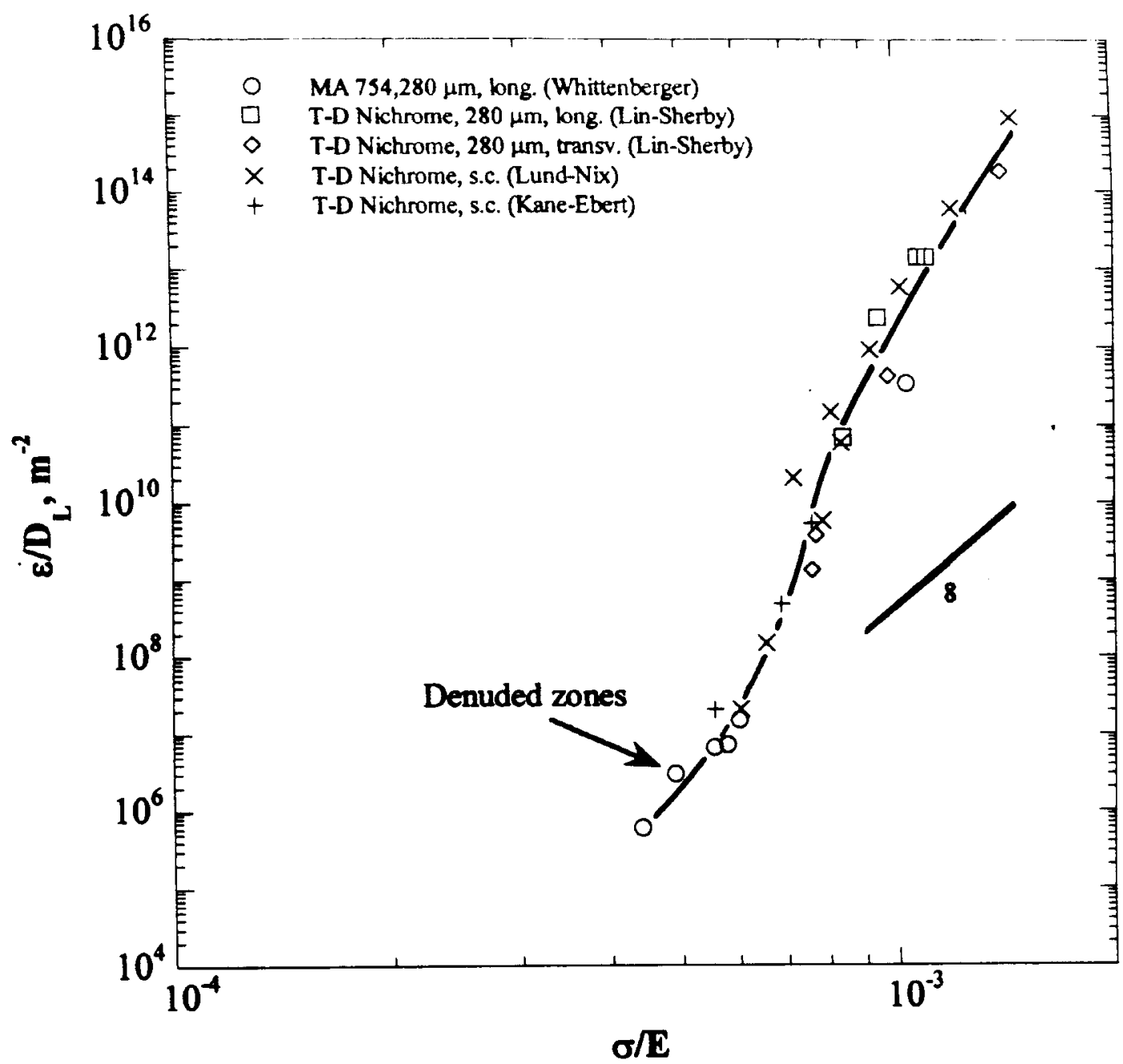

Fig. II 


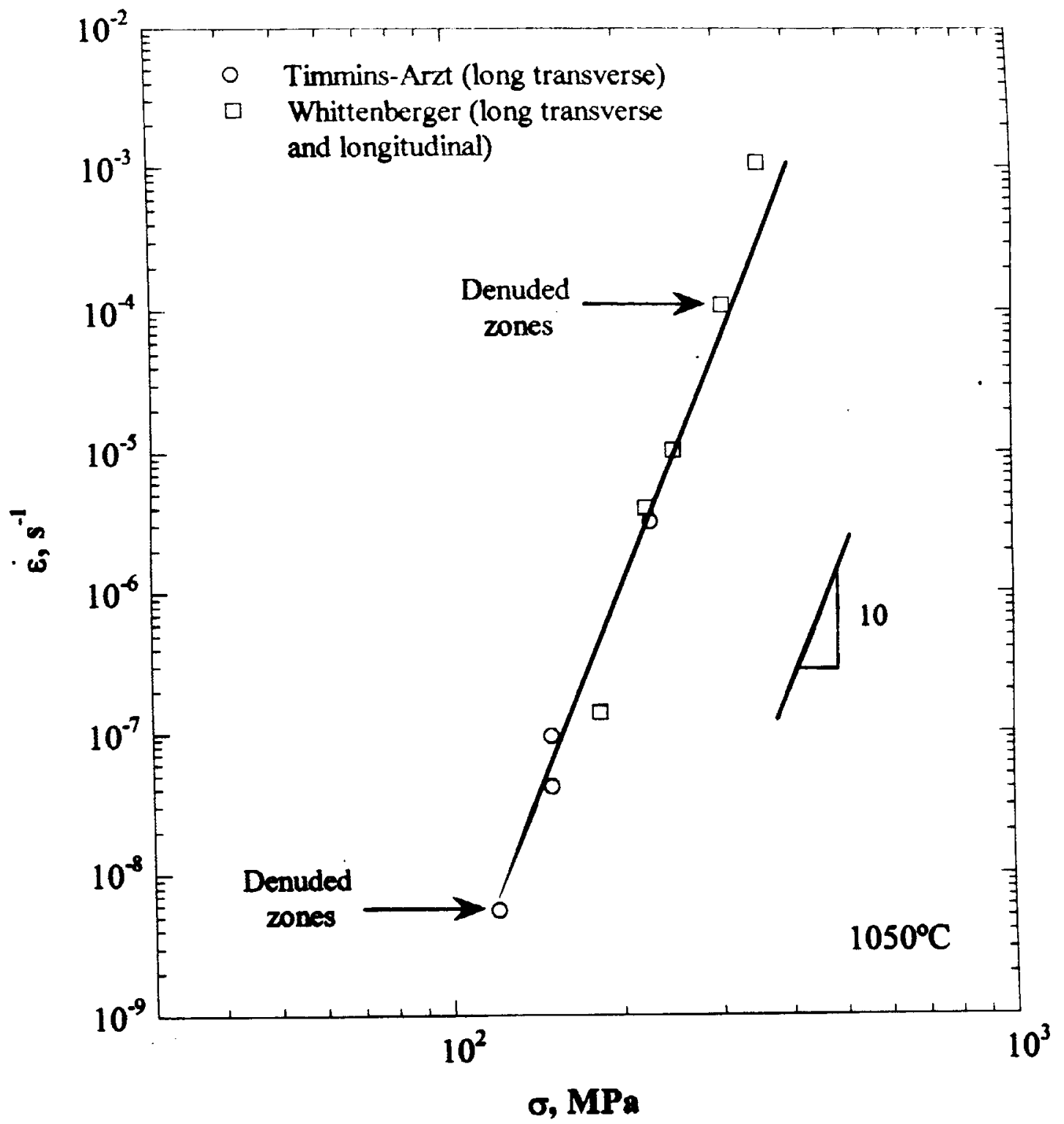

Fig. 12 


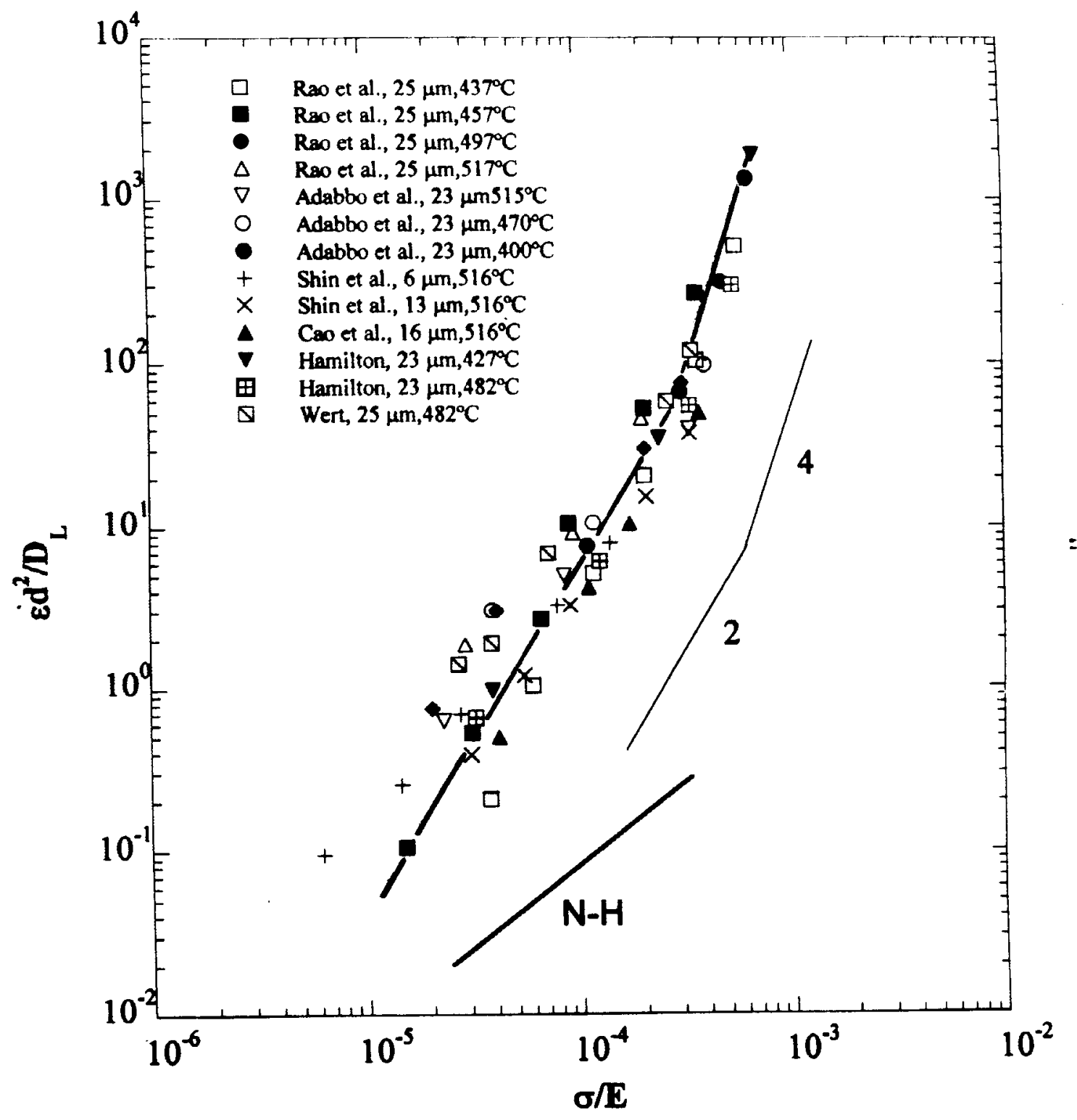

$$
\text { Fig. } 13
$$




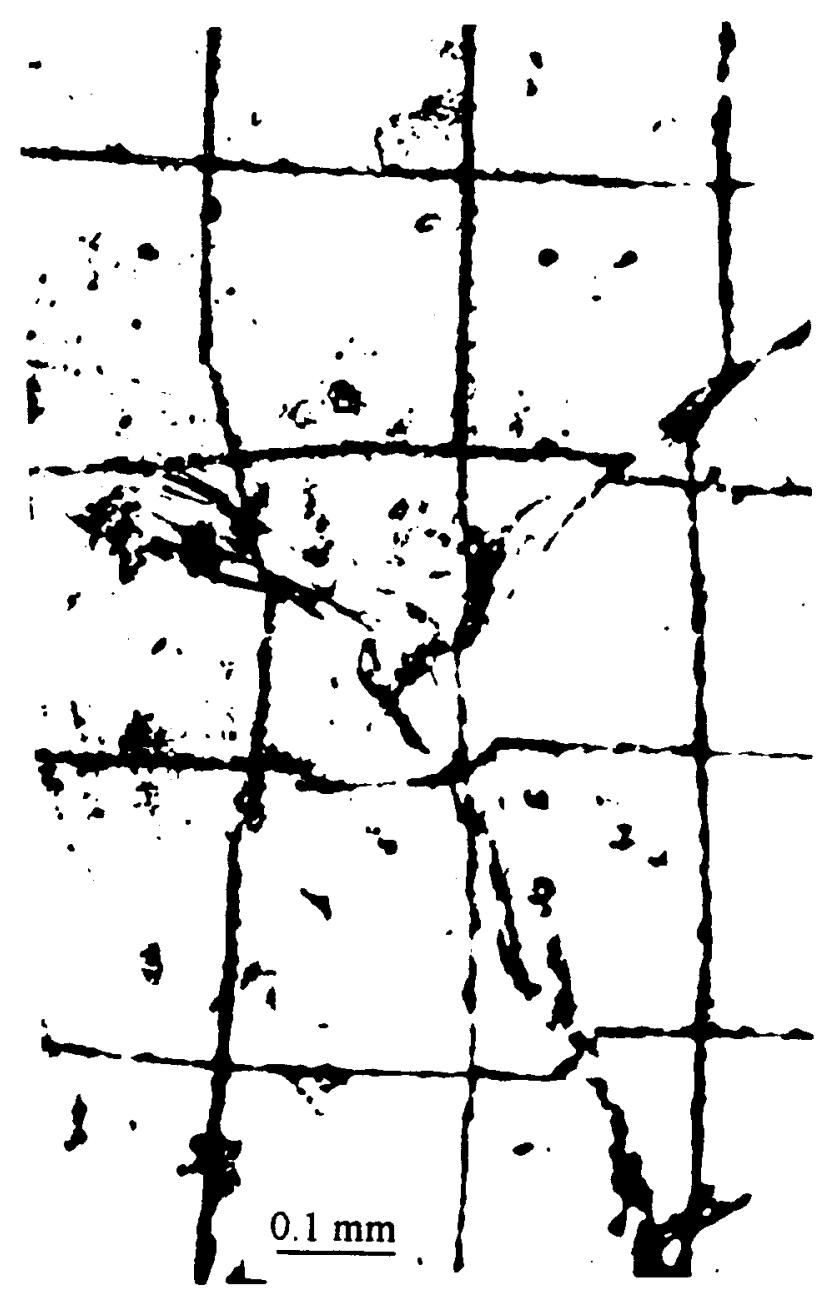

$a$

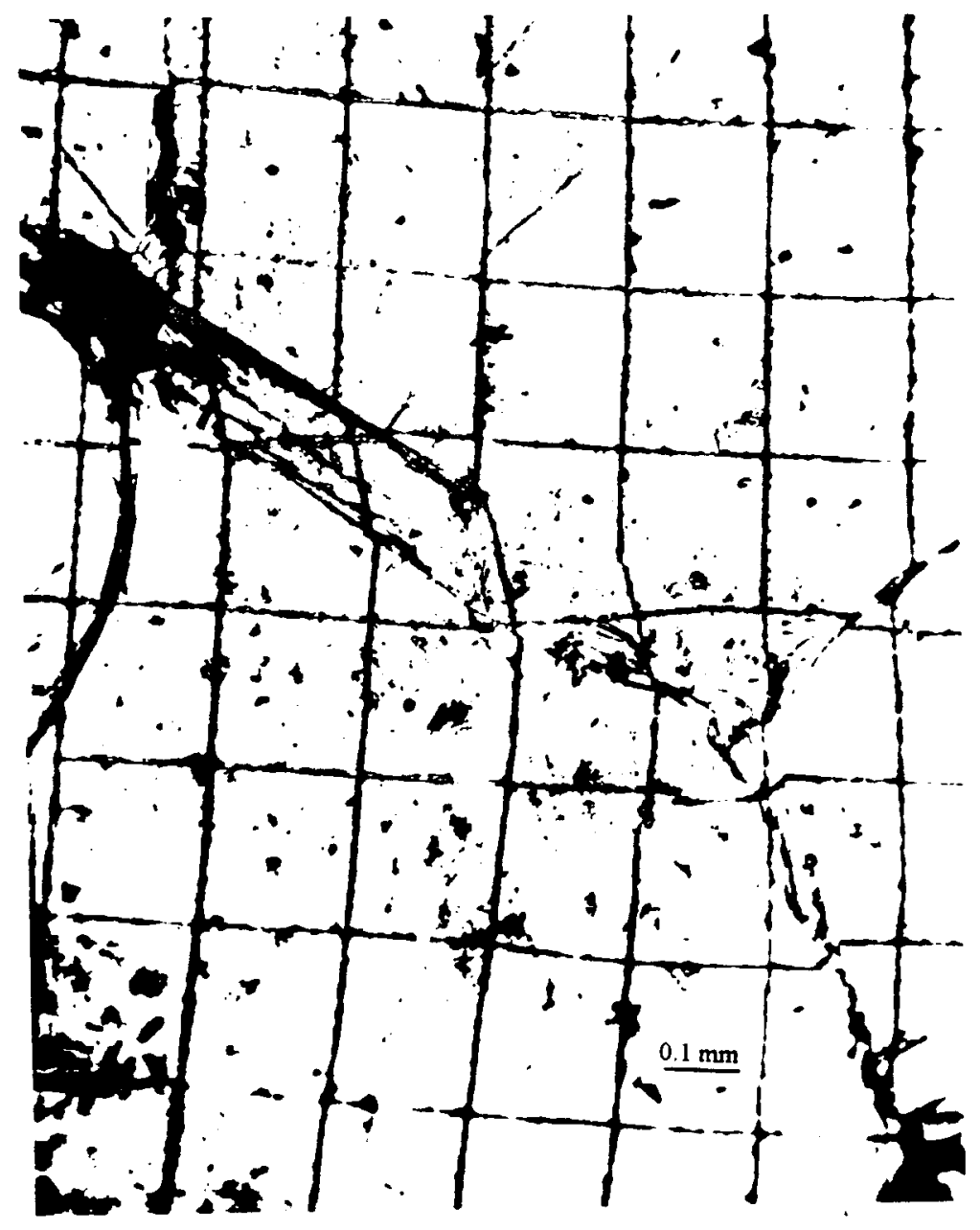

4

Fig 14 